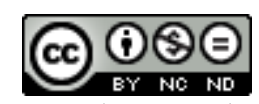

Protestantismo em Revista é licenciada sob uma Licença Creative Commons.

http:/ /dx.doi.org/10.22351/nepp.v43i2.2766

\title{
O homem e a morte no Antigo Testamento
}

\author{
The human and the death in Old Testament
}

Willibaldo Ruppenthal Neto*

\begin{abstract}
Resumo
Este artigo visa analisar a compreensão da morte no Antigo Testamento, demonstrando as três formas com que ela se apresenta, enquanto elemento linguístico, força cósmica e fim biológico. A morte, expressa pelas trevas e pelo deserto, é a fonte de impureza e sofrimento, completamente oposta não somente à vida como à própria criação. Assim como a vida, a morte também marca e define o ser humano, sendo entendida como o rompimento do relacionamento com Deus, somente podendo ser retomado por Deus. A vida após a morte, diferente do que muitos imaginam, não se apresenta como uma realidade positiva no Antigo Testamento, mas é antes uma situação de solidão e ausência, longe de ser desejada. O homem, completamente marcado pela mortalidade, encontra na morte seu trágico fim, cuja única luz de esperança reside não em sua natureza senão no poder de Deus que, sendo criador de todas as coisas, pode lhe criar novamente pela ressurreição.
\end{abstract}

\section{Palavras-chave}

Antropologia teológica. Antigo Testamento. Teologia bíblica.

\begin{abstract}
This article aims to analyze the understanding of death in the Old Testament, showing the three ways how it appears - as a linguistic element, a cosmic power, and biological end. The death, expressed by darkness and the desert, is the source of impurity and suffering, completely opposed not only to life but also to the creation. Like with life, death also defines the human being, once it is understood as the end of the relationship with God, that only God can remake. The afterlife, very different from what many imagine, is not a positive reality in Old Testament, but a lonely and absent situation, far from being something to wish for. The human, completely marked by mortality, finds in death his tragic end, which only light of hope isn't in his nature but in the power of God that being the Creator of all things, can create man again by resurrection.
\end{abstract}

[Texto recebido em maio de 2016 e aceito em janeiro de 2018, com base na avaliação cega por pares realizada por pareceristas ad hoc]

* Mestrando em História (UFPR). Graduado em História (UFPR). Bacharel em Teologia (FABAPAR). Integrante da Linha de Pesquisa Cultura e Poder/Núcleo de Estudos Mediterrâneos (NEMED/UFPR). Integrante do Grupo de Pesquisa Interpretação, Atualização e Transmissão dos Ensinos Bíblicos (FABAPAR). Bolsisa CNPq - Brasil. E-mail: willibaldoneto@hotmail.com 


\section{Keywords}

Theological Anthropology. Old Testament. Biblical theology.

\section{Introdução ${ }^{1}$}

A morte é mencionada no Antigo Testamento de inúmeras formas, ${ }^{2}$ assim como o substantivo מוֹ ("morte"), e o verbo ("morrer") são frequentemente utilizados nos textos veterotestamentários ${ }^{3}$. O estudo da morte é de importância fundamental na teologia do Antigo Testamento, especialmente quando se percebe que "é na interpretação do sentido da morte que a fé figura, nas ideias sobre o que se segue à morte". ${ }^{4}$ Compreendendo-se esta questão, logo se pode entender o porquê da importância do estudo dos cuidados com o cadáver e dos ritos funerários, uma vez que estas práticas se vinculam diretamente às ideias de vida após a morte presentes em uma cultura. Antes de abordarmos a questão da vida após a morte, entretanto, se faz necessário um estudo sobre a morte e o morrer na cultura judaica no contexto do Antigo Testamento, que são ideias diretamente relacionadas à perspectiva sobre a vida, uma vez que "o israelita não as considerava como esferas estritamente separadas, mas como fluidas e campos permutáveis de força que podiam interpenetrar-se e interagir" ${ }^{5}$

\section{A condição mortal do homem}

A vida propriamente humana se expressa em relação à própria morte, uma vez que é certo que todo homem um dia morrerá, pois, tendo sido feito do pó, ao pó retornará. ${ }^{6} \mathrm{O}$ homem é breve neste mundo, sendo sua vida senão como um sopro, ${ }^{7}$ algo

1 Este texto compõe parte do primeiro capítulo de meu Trabalho de Conclusão de Curso, O ser humano necessitado: as implicações do conceito de nefesh nas ideias de homem, vida e morte na antropologia do Antigo Testamento, defendido em 2015 nas Faculdades Batista do Paraná (FABAPAR), sob orientação do Prof. Igor Pohl Baumann. Foram feitas, porém, algumas modificações do texto original

2 FRERICHS, Wendell W. Death and Resurrection in the Old Testament. Word \& World, v. 11, n. 1, p. 14-22, 1991. p. 15.

3 FRERICHS, 1991, p. 18. Sobre estes termos, cf. SMICK, Elmer B. מוּת (mût). In: HARRIS, R. Laird; ARCHER Jr., Gleason L.; WALTKE, Bruce K. Dicionário Internacional de teologia do Antigo Testamento. São Paulo: Vida Nova, 1998. p. 820-822.

4 ROWLEY, H. H. A fé em Israel: aspectos do pensamento do Antigo Testamento. São Paulo: Teológica, 2003. p. 222.

5 FOHRER, Georg. História da Religião de Israel. Santo André: Academia Cristã; São Paulo: Paulus, 2012. p. 280.

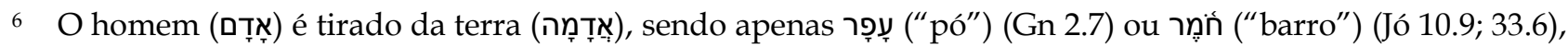
devendo retornar ao עָפר (Gn 3.19; S1 90.3). O texto de Eclesiastes 12.7 parece ir além, acrescentando um elemento que no homem que não se destina ao pó: "o pó [עָפ ] volte à terra, de onde veio, e o espírito [ריּ] volte a Deus, que o deu". Há quem veja aqui uma percepção de uma "destinação, não apenas alternativa, mas que prevê o elemento espiritual independente do físico" (FÄRBER, Sonia Sirtoli. Considerações sobre a morte no Antigo Testamento: aproximações entre teologia e tanatologia. Anais do Congresso Internacional da Faculdades EST, São Leopoldo, v. 1, 2012. p. 1053-1065. à p. 1056), porém, há ainda quem negue tratar-se aqui de uma esperança após a morte, a exemplo de Robert Martin-Achard: "Aqui se trata não do destino individual da alma, mas do princípio de vida concedido provisoriamente ao homem". MARTIN-ACHARD, Robert. Da morte à ressurreição: segundo o Antigo Testamento. Santo André: Academia Cristã, 2015. p. 48. Nos posicionamos ao lado de Martin-Achard, tanto pelo caráter 
que lhe coloca ao lado dos animais, ${ }^{8}$ também mortais, e distante de Deus, eterno: “à tua presença, o prazo da minha vida é nada. Na verdade, todo homem, por mais firme que esteja, é pura vaidade" (Sl 39.5b). ${ }^{9}$ A morte define o homem em sua humanidade, ${ }^{10}$ portanto, como um ser entre os animais, finitos, e distinto do criador, infinito. O homem, porém, distingue-se dos animais por saber que um dia morrerá. ${ }^{11}$ A consciência da morte lhe faz superior aos animais, mas a incapacidade de saber como morrerá12 ou mesmo de impedir sua morte, ${ }^{13}$ porém, lhe faz evidentemente muito inferior a Deus. Eis o lugar do homem a partir da concepção da morte no Antigo Testamento: acima dos animais, mas sempre abaixo de Deus.

\section{As três formas de morte no Antigo Testamento}

A morte no Antigo Testamento, segundo Lloyd Bailey, ${ }^{14}$ pode aparecer em três sentidos: 1) como metáfora ao que desvia as pessoas da vida planejada por Deus; 2) como poder ou força oposta à ordem criada; 3) como fim biológico de um ser vivo.

O primeiro sentido é muito utilizado no livro de Provérbios. Neste livro, fala-se em pessoas se dirigindo para a morte - como se esta fosse um caminho ou destino físico ${ }^{15}$ -

hebraico do livro de Eclesiastes, quanto pelo fato de que a vida após a morte no Antigo Testamento é representada justamente pelo עָָָ elemento da morada dos mortos, tal como veremos adiante. Sobre Adão e a terra, cf. COOPESS, Leonard J. אדם ('dm). In: HARRIS, R. Laird; ARCHER Jr., Gleason L.; WALTKE, Bruce K. Dicionário Internacional de teologia do Antigo Testamento. São Paulo: Vida Nova, 1998. p. 13-15.

7 Cf. Sl 39.5,11; 49.12,20; 82.7. Salmo 90.9 afirma que nós "gastamos os nossos anos como um sopro" (SBB). Outras traduções trazem o termo "murmúrio" (NVI), como "um conto que se conta" (ACRF), como "um pensamento" (RV), etc. A Bíblia Siríaca traz a expressão “como uma aranha”, acompanhada pela LXX, "meditaram como uma aranha" (ROWLEY, 2003, p. 222).

8 Cf. Sl 49.10-12,20; Ec 3.19s.

9 São utilizadas as seguintes versões bíblicas: Almeida Corrigida e Revisada Fiel (ACRF); Almeida Revista e Atualizada (ARA); Almeida Revisada Imprensa Bíblica (ARIB); American Standard Version (ASV); Bíblia de Jerusalém (BJ); Lutherbibel (LB); Septuaginta (LXX); Nova Bíblia Pastoral (NBP); Nova Versão Internacional (NVI); Reina-Valera (RV); Almeida Século 21 (S21); Sociedade Bíblica Britânica (SBB).

10 O Eclesiástico lembra da mortalidade do homem: "Porque no homem não podem existir todas as coisas pois o filho do homem não é imortal” (Eclo 17.30, BJ). H. H. Rowley lembra-nos que há MSS que trazem esta passagem de modo bastante diferente, até mesmo contraditório: "Os que praticam o que é do agrado dele, colherão o fruto da árvore da imortalidade" (Eclo 19.19). Este versículo é omitido na maioria das traduções (BJ, por exemplo), uma vez que estes manuscritos não são tidos como relevantes (ROWLEY, 2003, p. 222).

11 SMITH, Ralph L. Teologia do Antigo Testamento: história, método e mensagem. São Paulo: Vida Nova, 2002. p. 359.

12 Gn 27.2,7,10; Dt 31.27,29; Jz 13.7; Jó 21.23-26; 34.20; 36.14; S1 39.4-6; 49.10-12; 88.3-7,15; 90.3-6; Ec 3.2,19,20; 9.3; Is $40.6-8 ; 51.12$.

13 Ec 8.8. A morte é, portanto, o "caminho que todos devem trilhar". Cf. Nm 16.29; Js 23.14; 2 Sm 14.14; 1 Rs 2.2; Jó 14.1,2; 16.22; 30.23; S1 49.10; Ec 9.5; Is 51.12.

14 Cf. SMITH, 2002, p. 359-360. Uma organização semelhante é feita por Walter Brueggemann, que divide três formas distintas da morte se apresentar no Antigo Testamento: 1) biologicamente; 2) mitologicamente; 3) simbolicamente. ALEXANDER, Desmond. The Old Testament view of life after death. Themelios, v. 11, n. 2, p. 41-46, Jan. 1986. p. 41.

15 Pr $2.18 ; 5.5 ; 7.27 ; 14.12 ; 16.25$. 
em ações cuja consequência é a morte ${ }^{16}$ ou mesmo o livramento desta, ${ }^{17}$ e ainda sobre o poder da vida e da morte presente na língua. ${ }^{18} \mathrm{Em}$ todos estes casos, a morte serve como metáfora daquilo que desvia as pessoas da vida planejada por Deus, assim como a "vida" nestes textos refere-se à vida segundo a vontade de Deus, uma vida boa e plena. Isto não quer dizer que quem viver no caminho de vida não morrerá. Apesar de haver casos em que pessoas que andaram no caminho de Deus não viram a morte - a exemplo de Enoque, Elias e talvez Moisés ${ }^{19}$ - a morte não é evitada, mas tida de outra forma. Quem segue os caminhos do Senhor tem uma "boa morte" 20 no final de sua vida.

O segundo sentido é amplamente utilizado no livro dos Salmos, que trata as enfermidades e opressões dos inimigos como "uma irrupção da morte em sua vida e previsão da própria morte" ${ }^{21}$ de tal forma que o salmista pode ver-se já na sepultura, ${ }^{22}$ pois já está sob a ação do poder da morte, este poder que atua contra a ordem criada. A percepção do homem que sofre influência da morte enquanto "morto" é tão forte, que é bastante intensa e séria a oração que clama a Deus que lhe "tire da sepultura e lhe devolva a vida". ${ }^{23}$ Somente Deus pode devolver a vida, ${ }^{24}$ de tal forma que "a consequente libertação da enfermidade ou perigo é louvada como libertação da sepultura e do abismo" ${ }^{25}$ Em algumas situações a morte é personalizada a tal ponto que Jeremias chega inclusive a afirmar que "a morte subiu e penetrou pelas nossas janelas e invadiu as nossas fortalezas, eliminando das ruas as crianças e das praças, os rapazes" . 26

$6 \operatorname{Pr} 8.36 ; 11.19 ; 16.14 ; 21.6$

$17 \operatorname{Pr} 10.2 ; 11.4 ; 11.19 ; 12.28 ; 13.14 ; 14.27 ; 19.18$.

$8 \operatorname{Pr} 18.21$.

19 O arrebatamento, apesar de raro, está destacado no Antigo Testamento. Há dois casos evidentes de arrebatamento - Enoque (Gn 5) e Elias (2 Rs 2) - assim como um caso questionável - Moisés (segundo tradições judaicas helenísticas, principalmente em Alexandria). Mais presente nos textos, porém, do que os casos relatados, são as próprias expectativas de possibilidade de arrebatamento, que é percebido quase como uma terceira via: entre esta vida e a existência degradada no לִ̣ há a possibilidade de uma ligação de vida com Deus. Assim, o salmista expressa sua confiança de que "Deus redimirá a minha vida da sepultura e me levará para si" (Salmo 49.15, NVI). O uso do arrebatamento como figura de linguagem e a confiança neste estão fundamentados na comunhão para com Deus, uma vez que Deus toma para si quem tem intimidade com ele, assim como a "ideia do arrebatamento, espera-se uma ligação com Javé que nem a morte corporal pode interromper". WOLFF, Hans Walter. Antropologia do Antigo Testamento. São Paulo: Hagnos, 2008. p. 175.

20 Sobre a "boa morte" e a "má morte", Cf. ALEXANDER, 1986, p. 41-42; SPRONK, Klaas. Good death and bad death in ancient Israel according to biblical lore. Social Science E Medicine, v. 58, p. 987-995, 2004.

21 FOHRER, 2012, p. 281.

22 Sl 18.4-5; 88.3-5; Cf. também Is 38.10.

23 Cf. S1 71.20.

24 Não somente Deus pode devolver a vida, como esta forma de "morte" é decorrência de uma ausência divina: "a morte é compreendida como um processo e este começa quando Deus deixa seu povo e entrega-lhes a um inimigo ou outra força de destruição" JOHN, E. C. The Old Testament Understanding of Death. Indian Journal of Theology, v. 23, p. 123-128, 1974. p. 125. Esta percepção de John segue nesta segunda forma de "morte" no Antigo Testamento, sendo compreendida "como um poder maligno estendendo seu domínio sobre a esfera da vida" (JOHN, 1974, p. 125).

25 FOHRER, 2012, p. 281. Cf. Sl 30.3; 86.13.

26 Jr 9.21. 
O terceiro sentido é o sentido mais literal, de morte enquanto fim biológico de um ser vivo. Mesmo sendo de caráter literal, também pode trazer consigo uma ideia bastante forte na mentalidade judaica, que é a morte como "estar em silêncio". O fim biológico marca também o fim da capacidade de se pronunciar, que define o ser humano enquanto propriamente humano. O cadáver é consumido por vermes, ${ }^{27}$ mas as palavras ditas em vida, permanecem. A incapacidade de fala tem como consequência tanto a impossibilidade de contato com Deus, ${ }^{28}$ como de louvor a Ele, ${ }^{29}$ pois Deus é um Deus de vivos, e não de mortos. Mesmo que Deus tenha poder sobre a morte, esta marca uma ruptura no contato entre Deus e o homem. Cabe a quem permanecer vivo, que ainda tiver o fôlego de vida, e a capacidade de respirar, louvar a Deus: “Todo ser que respira louve ao Senhor" (Sl 150.6).

\section{Expressões da morte no Antigo Testamento}

Assim como a vida se expressa por elementos da natureza como a luz, a água e a vegetação, também a morte é expressa por elementos semelhantes, sendo, naturalmente, justamente os opostos a tais expressões da vida, a saber, as trevas e o deserto. A relação entre morte e trevas se dá não somente como paralelismo na relação de antítese ao binômio vida/luz, como ainda se desenvolve em um aprofundamento teológico sobre a ideia de

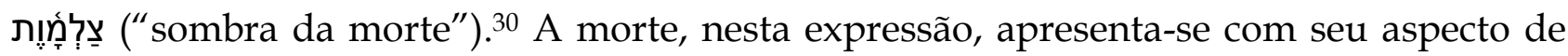
mistério e de terror, cobrindo a humanidade com seu manto de trevas, evidenciando seu aspecto de vazio. A relação entre morte e deserto vai, também, para além da oposição à ideia de relação entre vida e vegetação, relacionando-se ainda como oposição à expressão da vida pela água. O deserto, portanto, acaba sendo por excelência a região da morte. ${ }^{31}$

27 Is $14.10-11$

28 Sl 88.5, 10-12; Jó 7.21b.

29 Sl 88.10-12; 115.17; Is 38.18-19.

30 E. C. John bem nos lembra da importância do contraste para a compreensão das ideias: “Assim como a luz não pode ser compreendida exceto em sua relação com as trevas, a morte não pode ser compreendida senão em relação à vida" (JOHN, 1974, p. 123). Um termo importante na relação entre trevas e morte é

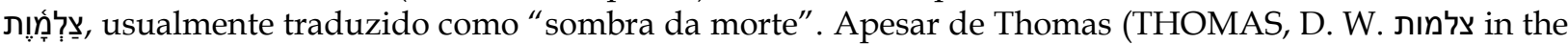
Old Testament. Journal of Semitic Studies, v. 7, p. 191-200, 1962) e Mazzini (MAZZINI, Giovanni. On the meaning of SALMAWET, a discussed word in the Old Testament. Studi Epigrafici e Linguistici sul Vicino Oriente Antico, n. 16, p. 79-83, 1999) apontarem para um significado do termo enquanto "sombra profunda", mediante a raiz hebraica צלמ ("ser escuro") e não ("morte"), há quem entenda que se trata de um termo que estreita relações entre trevas e morte, mesmo em alguns casos somente, tal como Anthony P. Stone. Cf. STONE, Anthony P. Does "Shadow of Death" mean "Deep darkness"? Journal of The Chicago Society of Biblical Research, v. LI, p. 53-57, 2006. De toda forma, "a etimologia e o significado (...) não são claros". MICHEL, Walter L. SLMWT, "Deep darkness" or "Shadow of Death"? Biblical Research, v. 29, p. 5-20, 1984. p. 11.

31 Mark S. Smith lembra que a ideia ugarítica e hebraica da montanha dos deuses é também relacionada a um jardim (Ezequiel 28). SMITH, Mark S. O memorial de Deus: história, memória e a experiência do divino no Antigo Israel. São Paulo: Paulus, 2006. p. 136. O deserto é relacionado ao She'ol, habitação dos mortos, enquanto terra de ninguém e onde crescem sarças e espinhos, em contraste com a terra prometida, onde mana leite e mel (MARTIN-ACHARD, 2015, p. 60-61). Na cultura ugarítica, a estepe tem o sentido de marcar a divisão entre a zona das atividades humanas e a zona dos perigos (SMITH, 2006, p. 137). Este 


\section{A vida após a morte no Antigo Testamento}

A morte é marcada tanto pela sua certeza como pela sua irreversibilidade. É o destino de todos os homens, e um caminho sem volta. Mas, para onde ela conduz? Qual a ideia de vida após a morte presente no Antigo Testamento? Antes de se explicar a ideia dos judeus antigos sobre a vida após a morte, se faz necessário comentar sobre suas relações com os mortos.

Apesar do embalsamamento nunca ter sido praticado em Israel e não estar presente no Antigo Testamento senão nos casos de Jacó e José em decorrência da relação destes com o Egito, ${ }^{32}$ havia procedimentos em relação ao sepultamento dos mortos que deveriam ser seguidos e ainda outros que deveriam ser evitados. A falta de sepultura, por exemplo, deixando o corpo exposto aos animais, ${ }^{33}$ assim como queimar o corpo, ${ }^{34}$ eram considerados ultrajes e mesmo maldições, ${ }^{35}$ que deveriam ser evitados em relação às pessoas queridas. Para os entes queridos mortos, além dos ritos de luto de rasgar-se as roupas, vestir-se de saco, lamentar-se e jogar-se cinza sobre a cabeça, também havia ritos bastante estranhos presentes no contexto do Antigo Testamento, tais como os ritos alimentares que, apesar de serem condenados e ridicularizados em textos canônicos ${ }^{36} \mathrm{e}$ mesmo apócrifos, ${ }^{37}$ apresentam-se nas escavações que indicam uma considerável presença da prática de depositar alimentos nos túmulos seguindo o costume cananeu. ${ }^{38}$ Todos estes cuidados em relação aos cadáveres parecem indicar não somente uma ideia de possibilidade de interferência na situação dos mortos, como ainda um aparente medo em relação a estes.

Mas como conciliar este aparente medo dos mortos e preocupação com os cadáveres e a perspectiva da morte como fim absoluto da vida, presente em textos tais como 2 Samuel 14.14a: "Porque morremos, e somos como água derramada sobre a terra, que não se pode mais juntar" (SBB)? Alguns estudiosos têm apontado como resposta a ideia de que os israelitas conviviam e mantinham duas visões sobre o que acontece após a morte. ${ }^{39}$ Apesar de haver estudiosos que apontam para uma sucessão entre uma e outra

contraste entre a terra do homem com o deserto é marcado pelo fato de que o segundo "sempre é um lugar maligno". MOWVLEY, H. Health and Salvation in the Old Testament. The Baptist Quarterly, v. 22, n. 3, p. 100-113, Jul. 1967. p. 102. O deserto é posteriormente associado aos demônios (Tobias 8.3; I Enoque 10.6-9; Mt 12.43; Patai 81.459).

32 Gn $50.2,3,25$.

331 Rs 14.11; Jr 16.4; 22.19; Ez 29.5.

34 Gn 38.24; Lv 20.14; 21.9.

35 DE VAUX, Roland. Instituições de Israel no Antigo Testamento. São Paulo: Vida Nova, 2008. p. 80-81.

36 Dt 26.14.

37 Bar 6.26; Eclo 30.18.

38 DE VAUX, 2008, p. 84.

39 Cf. por exemplo: MARTIN-ACHARD, 2015, p. 35; JOHN, 1974, p. 127. 
percepção, ${ }^{40} \mathrm{o}$ fato de que havia duas concepções bastante divergentes, que possivelmente se misturavam na mente dos israelitas sem que fossem percebidas como excludentes, ${ }^{41}$ é bastante recorrente nos estudos do Antigo Testamento. Seguindo esta perspectiva, de um lado haveria a crença no fim absoluto com a morte, enquanto de outro estaria a crença em uma existência degradada e relativa no ("sepulcro", "mundo dos mortos"). A existência de uma pluralidade de percepções na mentalidade judaica não deve ser estranhada, ${ }^{42}$ assim como não impede que venhamos a definir elementos constituintes. Utilizaremos aqui, portanto, os textos que seguem a segunda concepção de realidade póstuma, de que a morte não é o fim absoluto, que se dá especialmente na relação com o שְֵׁוֹ.

\section{O mundo dos mortos no Antigo Testamento}

É certo que mesmo o ẹ pode estar relacionado em muitos textos ao fim da existência, uma vez que a "descida ao שִׁאול" em muitos casos "não significa mais do que a referência ao enterro como fim da vida". ${ }^{43}$ Mesmo assim, porém, podemos perceber a crença em um "mundo dos mortos", o quẹi, que "não é comparável nem ao Hades dos gregos nem ao inferno e purgatório", 44 uma vez que possui especial singularidade.

A origem etimológica e o significado exato da palavra שệi são desconhecidos a nós, apesar das várias hipóteses, ${ }^{45}$ mas, como bem lembra Robert Martin-Achard, mesmo assim "o que ela representa para os israelitas é muito claro" ${ }^{46} \mathrm{Em}$ primeiro lugar, cabe

40 A. Lods defende esta posição, porém Martin-Achard lhe contraria afirmando que "essas diversas correntes mais ou menos independentes entre si em suas origens coexistiram sem dúvida no povo de Israel" (MARTIN-ACHARD, 2015, p. 35).

41 Robert Martin-Achard bem explica que a aparente contradição "está constituída por diversas tradições, escalonadas no tempo, que se sobrepõem umas às outras; finalmente, elas partem de uma psicologia diferente da nossa, que aceita perfeitamente afirmações que para nós nos parecem se excluir" (MARTINACHARD, 2015, p. 34).

42 Mesmo Hans Walter Wolff, que define diversos elementos constituintes da mentalidade judaica, chega a afirmar que na verdade "nada é mais estranho ao pensamento do Antigo Testamento do que uma sistemática antropológica, é interessante e esclarecedor encontrar tendências convergentes em suas diversas camadas" (WOLFF, 2008, p. 336).

43 WOLFF, 2008, p. 167. Neste sentido, Wolff aponta os seguintes textos: Gn 42.38; 44.29, 31; Is 38.10, 17; Sl 9.16, 18; 16.10; 49.10, 16; 88.4-7, 12s; Pv 1.12.

44 FOHRER, 2012, p. 284. Robert Martin-Achard coloca-se em posição contrária à de Georg Fohrer, afirmando que o e ex israelita é "totalmente comparável ao Hades dos gregos, e ao Aralu dos assíriosbabilônios" (MARTIN-ACHARD, 2015, p. 54). Certamente possui suas relações com o Aralu, tal como evidenciado nas notas de rodapé do presente trabalho, porém a comparação com o 'Ạđn s só é possível quando se pensa no Ậ́n em seu sentido homérico e não o posterior (principalmente a partir de Sócrates). Mesmo assim, porém, cabe destacar a singularidade do caso israelita.

45 Robert Martin-Achard (2015, p. 54) indica que há quem aponte para a relação com o verbo "perguntar" (E. König, O. Schilling), com a ideia de "profundidade" (Vollers, E. Sellin), com o Oeste, onde o Sol se põe (W. Eichrodt), com o deserto (L. Köhler), ou ainda com paralelos babilônicos (W. F. Albright). Cf. ALBRIGHT, W. F. The Etymology of Še'ôl. American Journal of Semitic Languages and Literatures, v. 34, n. 3, p. 209-210, Apr. 1918.

46 MARTIN-ACHARD, 2015, p. 55. 
entender-se que não se trata de um lugar, mas antes de um estado, ${ }^{47}$ uma situação de nãovida, uma ruptura na existência.

É assim que o שִׁ incorpora os vários elementos já apresentados em relação à morte: a impossibilidade de volta, ${ }^{48}$ as trevas, ${ }^{49}$ o pó, ${ }^{50}$ o silêncio ${ }^{51}$ e o esquecimento. ${ }^{52}$ Todos estes elementos visam apontar não somente para a sepultura como também para a solidão e a inércia. O mundo dos mortos apresenta-se como "um cemitério gigante, em que cada um tem seu lugar",53 de tal modo que não se apartam apenas da presença dos outros como também e principalmente da presença do Deus vivo. A morte e o לִ são associados com o deserto justamente pelo mundo dos mortos ser "um mundo onde reina a ausência radical", 54 uma verdadeira "não-terra", na qual "não há nada ativo e dinâmico". ${ }^{55}$ Não há vida nem atividade, pois para o povo judeu, a vida, "tanto individual como comunitária, não encontra outra realidade além da presença do Deus vivo". ${ }^{56}$ Sendo assim, o rompimento do relacionamento com Deus é "o caráter mais insuportável" do לִ Em parte, este efeito da morte é também presente na ideia de que o contato com a morte tocando cadáveres, ossos ou túmulos - gera impureza no homem. ${ }^{58}$ Assim, se torna ơ ("impuro") diante de Deus "tudo que de qualquer modo esteja em conexão com a morte". ${ }^{59}$ Tal impureza, decorrente do contato com a morte, é a impureza quase por excelência, uma vez que "não é possível haver maior impureza". ${ }^{60}$ Esta seriedade com que a morte é tomada, possivelmente tem como intuito estabelecer um corte entre a tradição de contato com os mortos e a religião judaica. ${ }^{61}$

47 MARTIN-ACHARD, 2015, p. 59.

482 Sm 12.23; 14.14; Jó 7.8ss; 10.21. Também para os mesopotâmicos a morte é o caminho do qual não há volta, conforme é a descrição do sentido da morte no Épico de Gilgamesh: "Para a terra de onde não há retorno [...]; Para a casa da qual nunca sai quem entra; Para a estrada cujo caminho não tem volta..." SOARES, Elizangela. Antigas variações sobre a vida após a morte. Revista Oracula, São Bernardo do Campo, v. 2, n. 4, 2006. p. 1-29. p. 11. Cf. Jó 16.22.

49 Jó 10.21ss; 18.18; 38.17; Sl 49.20; 88.13.

50 Sl 22.30; 30.10; Jó 2.8; 20.11; 30.19; Is 26.19; Dn 12.2. Assim como a morte é apresentada como "voltar ao pó", e não subir aos céus (S1 104.29; Jó 34.15), o reino dos mortos é marcado pelo pó. No Épico de Gilgamesh, a habitação dos mortos é referida como "onde o pó é o alimento [e] a argila o sustento" (SOARES, 2006, p. 11).

51 Sl 31.18; 94.17; 115.17.

52 Sl 88.10-12.

53 MARTIN-ACHARD, 2015, p. 55.

54 MARTIN-ACHARD, 2015, p. 59.

55 FOHRER, 2012, p. 284.

56 MARTIN-ACHARD, 2015, p. 59.

57 MARTIN-ACHARD, 2015, p. 59.

58 Cf. Lv 11.24-40; Nm 19.11-22.

59 WOLFF, 2008, p. 169.

60 WOLFF, 2008, p. 170.

61 Javé se coloca em oposição contra todas as formas de culto aos mortos, cf. Dt 14.1s; 18.11; Lv 19.27s; 20.6,27; Jr 41.5. Talvez por isso seja recorrentemente mencionado como "Deus vivo" em polêmicas contra outros deuses: cf. Js 3.10; 2 Rs 19.4; Os 2.1. WOLFF, 2008, p. 169. Para outras possíveis explicações, cf. JOHNSTON, Philip S. Shades of Sheol: Death and Afterlife in the Old Testament. Leicester: Apollos; Downers Grove: InterVarsity Press, 2002. p. 43-45. 
O israelita sabe do poder e supremacia de Deus sobre a morte e o mesmo assim a um primeiro momento nos textos do Antigo Testamento - pelo menos no que diz respeito aos textos pré-exílicos ${ }^{62}$ - a morte não se apresenta com nenhuma esperança. Será somente após o exílio e com transformações tanto na cultura quanto na teologia dos israelitas que haverá esperança - não para uma vida após a morte, mas justamente para a vitória de Deus sobre a morte. A ressurreição, por exemplo, não se desenvolve no Antigo Testamento a partir de uma ideia de imortalidade da alma, ou de um destino após a morte reconfigurado, mas da vitória de Deus sobre esta realidade sem esperança que é a morte e o ${ }^{6}$ É no poder de Deus somente que reside toda a esperança humana: Deus irá destruir a morte. ${ }^{64}$

\section{O desejo pela morte no Antigo Testamento}

Apesar do futuro esperado após a morte ser uma realidade dificilmente desejada, o desejo pela morte aparece no Antigo Testamento. Em alguns casos, o efeito da força da morte era tão desesperador sobre algumas pessoas que estas chegam a pedir a morte biológica para Deus, porém, "só na aflição extrema pode haver um desejo da morte". ${ }^{65}$ Certamente o caso mais dramático é o de Jó que, estando em situação miserável, pede a Deus a sua própria morte. ${ }^{66}$ Também Moisés, ${ }^{67}$ Elias, ${ }^{68}$ Jeremias $^{69}$ e Jonas ${ }^{70}$ desejam morrer e solicitam a Deus que termine com suas vidas. Apesar da doença ser um fator no desejo pela morte no Antigo Testamento, o sofrimento psicológico também pode resultar neste desejo. Mesmo assim, porém, a definição do fim da vida era sempre levada a Deus. ${ }^{71}$ Nenhum dos "sofredores" mencionados se suicida. Mas, e quanto aos casos de suicídio no Antigo Testamento?

62 FÄRBER, 2012; JOHN, 1974, p. 127.

63 Mesmo o livro do Apocalipse de João é marcado por esta concepção israelita, de tal forma que é evidenciada a vitória de Deus com a seguinte descrição: "A morte e o Hades foram lançados no lago de fogo. Esta é a segunda morte, o lago de fogo" (Ap 20.14, SBB). Cabe destacar que os judeus se valeram do

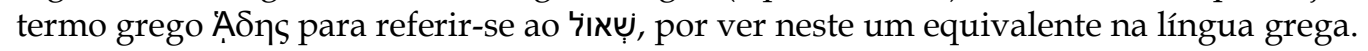

64 Cf. especialmente Is 25.8; 26.19. Para uma interpretação dos textos do Antigo Testamento que podem indicar uma vitória sobre a morte e um anúncio da ressurreição, cf. MARTIN-ACHARD, 2015, p. 93-164.

65 WOLFF, 2008, p. 180.

66 Jó 7.14. Diversos texto de Jó, de forma muito diferente do que é usual no Antigo Testamento, dão uma impressão positiva da morte, como uma espécie de "amiga", como indicado por Philip S. Johnston. Cf. JOHNSTON, 2002, p. 27-28. Muito mais recorrente, porém, é a imagem da morte como "inimiga". Cf. JOHNSTON, 2002, p. 28-31.

$67 \mathrm{Nm} 11.15$.

681 Rs 19.4 .

69 Jr 20.14-18.

70 Jn 4.3 .

71 A decisão sobre o fim de uma vida é uma questão importante no debate ético e teológico atual sobre a questão da eutanásia. Cf. VON SINNER, Rudolf. Quem decide sobre o fim da vida? Estudos Teológicos, São Leopoldo, v. 53, n. 2, p. 282-296, jul./dez. 2013. 
O suicídio é bastante raro no Antigo Testamento, aparecendo em somente seis situações, $^{72}$ e se dando por diversas razões: ${ }^{73}$ pode ser uma questão de honra, ${ }^{74}$ de vingança, ${ }^{75}$ de medo. ${ }^{76}$ Em geral, é uma ação bastante sentimental, uma decisão quase precipitada, uma resposta rápida à situação do momento, decorrente de uma oportunidade percebida. Em nenhum destes casos, porém, é uma rejeição da vida: quase todos os casos envolvem já um risco de vida, sendo situados em batalhas.

Somente no caso do suicídio de Aitofel, relatado em 2 Samuel, se trata de uma atitude planejada, de modo que tem tempo para ir para sua casa e colocar em ordem os seus negócios antes de se enforcar. 77 O suicídio de Aitofel, porém, não é decorrente de uma rejeição da vida, senão de uma precaução perante a possibilidade de sua família perder a posse de seus bens, que poderiam passar ao rei se fosse incriminado. ${ }^{78}$ Como bem apontou Yael Shemesh, seu suicídio é o de alguém que antecipa eventos futuros, ${ }^{79}$ tomando a decisão em benefício de sua família: sabia que de toda forma morreria em breve, mas se fosse pelas mãos de outro, poderia acabar não deixando nada de herança.

Em todos os casos de suicídio, portanto, não há um desejo de morte pois, com a única exceção de Sansão, a morte já estava aos olhos dos que escolheram o suicídio. Em todos os casos, "é o resultado de circunstâncias extremas e completamente sem esperanças". ${ }^{80}$ É interessante de se notar que, no caso de Sansão, que pode de fato ter desejado encerrar sua vida sem esperança, repleta de dor e humilhação, sem liberdade e sem visão, ${ }^{81}$ ao mesmo tempo precisa solicitar a Deus que lhe dê força para derrubar as

72 Cf. SHEMESH, 2009.

73 Quanto ao suicídio no Antigo Testamento, cf. SHEMESH, 2009.

74 Abimeleque: após sofrer um ferimento mortal por uma pedra de moinho atirada por uma mulher, pede a seu servo que o mate para que não morra pelas mãos de uma mulher (Jz 9.54). O escudeiro de Saul: após o suicídio de Saul, seu escudeiro também se suicida (1 Sm 31.5). Yael Shemesh indica um caso extraordinário de honra e lealdade, uma vez que não havia entre os judeus o costume, presente durante muito tempo no Japão, p.e., dos escudeiros seguirem seus senhores na morte (Junshi). SHEMESH, 2009, p. 163.

75 Sansão: já cego, Sansão decide derrubar as colunas do local onde estava para derrubar o mesmo sobre os filisteus, a fim de se vingar (Jz 16.25-31). Seu pedido por força a Deus deixa clara a motivação por vingança (Jz 16.28). Zinri: vendo que a cidade de Tirza estava sendo tomada, decidiu queimar o castelo real e morrer lá dentro (1 Rs 16.18-19).

76 Saul: após perder uma batalha, pede a seu escudeiro que lhe matasse, terminando por se matar (1 Sm 31.3-5), em decorrência do medo que estava (1 Sm 31.3). Shemesh lembra que é provável que se trate aqui de um pedido por uma morte de misericórdia, em decorrência de um temor em relação a uma possível tortura nas mãos dos inimigos. SHEMESH, 2009, p. 161.

$772 \mathrm{Sm}$ 17.23.

78 Esta interpretação já havia sido indicada pelo Talmude (Sanhedrin 48b). Cabe lembrar que após Jezabel ordenar a morte de Nabote, Acabe toma posse de sua vinha (1 Rs 21.8-16). Cf. SHEMESH, 2009, p. 164. O texto de 2 Samuel 16.23 deixa claro que Aitofel era um homem sábio.

79 SHEMESH, 2009, p. 164.

80 SHEMESH, 2009, p. 166. Philip S. Johnston também indica que "tudo suporta a visão de que a vida era de suprema importância aos israelitas, e não deveria ser desprezada ou tirada sem uma boa causa. $\mathrm{O}$ suicídio pode ter ocorrido muito ocasionalmente e em circunstâncias trágicas, mas dificilmente era algo normal, natural ou aceitável" (JOHNSON, 2002, p. 38-39).

81 SHEMESH, 2009, p. 159. 
colunas. Assim, Sansão, como Aitofel, pode receber o sepultamento junto a seus pais, ${ }^{82}$ não sendo reprovado pela tradição de Israel.

\section{Considerações finais}

Na visão semítica do Antigo Testamento, o homem apresenta-se como um serpara-a-morte, ${ }^{83}$ marcado pela sua efemeridade, ao mesmo tempo que possui autoridade e proeminência sobre os demais seres vivos. A morte se apresenta como uma verdadeira sombra, que paira sobre o homem, lhe lembrando de sua mortalidade. Nem o homem deseja a morte, nem Deus deseja que o homem morra. ${ }^{84}$ Mesmo assim, porém, a vida do homem, mesmo que breve, pode alcançar significado, especialmente em suas relações com a criação, com os outros e principalmente com Deus. A morte, por outro lado, recorda a limitação do homem, ser marcado pela finitude, totalmente exposto a este poder que somente Deus pode sobrepujar. É em Deus, criador de todas as coisas e Senhor sobre tudo, que estava não apenas a atenção do homem do Antigo Testamento, como também a sua esperança.

É em Deus, e não em uma realidade imaterial do homem, que há a esperança para além da morte: "seu destino não depende de sua natureza, mas sim do Deus vivo". ${ }^{85}$ Assim, a morte não aparece ao judeu como um desejo, tal como aos filósofos gregos, ${ }^{86}$ uma vez que, para o judeu, a morte "não significa uma melhora de sua condição, não representa um bem ou uma libertação", 87 mas antes é um rompimento com o que o homem possui de mais precioso - o relacionamento com Deus, o qual apenas Deus, que possui poder sobre a morte, pode reatar. Como indica Alain Marchadour, cada "povo faz a experiência da morte dentro de uma cultura, por meio de uma linguagem, tendo por referência uma antropologia e uma cosmologia graças às quais se organizam todos os seus códigos simbólicos". 88 No caso judaico, porém, tanto a linguagem, como ainda a

82 Cf. Jz 16.31; 2 Sm 17.23.

83 MARTIN-ACHARD, 2015, p. 38.

84 O texto de Salmos 116.15 é recorrentemente mal compreendido, em decorrência de erros de tradução. A tradução de Almeida traz: "Preciosa é aos olhos do Senhor a morte dos seus santos" (ARA). Mais corretas, porém, são as versões da Almeida Século 21: "A vida dos seus seguidores é preciosa aos olhos do SENHOR" (S21, grifo nosso); e da Nova Bíblia Pastoral: "É custosa aos olhos Javé a morte de seus fiéis" (NBP, grifo nosso). O sentido original, tal como é presente em todo o Salmo 116, é o de que a vida é valiosa. A confusão se dá pela palavra hebraica יִּי ("precioso", "caro", "custoso", "pesado"), que possui o sentido de "custosa", ou seja, que sai caro, que é difícil. A S21 optou por manter a tradução por "preciosa" e mudar a palavra "morte" por "vida", se afastando do texto original, mas preservando o sentido.

85 MARTIN-ACHARD, 2015, p. 34.

86 "Embora os homens não o percebam, é possível que todos os que se dedicam verdadeiramente à filosofia a nada mais aspirem do que a morrer e estarem mortos" (Platão, Fédon, 64a).

87 MARTIN-ACHARD, 2015, p. 49.

88 MARCHADOUR, Alain. Morte e vida na Bíblia. São Paulo: Paulinas, 1985. p. 7. 
antropologia e a cosmologia, são necessariamente dependentes da própria concepção teológica. ${ }^{89}$ A antropologia do Antigo Testamento, é, portanto, necessariamente teológica.

\section{Referências}

ALBRIGHT, W. F. The Etymology of Še'ôl. American Journal of Semitic Languages and Literatures, v. 34, n. 3, p. 209-210, Apr. 1918.

ALEXANDER, Desmond. The Old Testament view of life after death. Themelios, v. 11, n. 2, p. 41-46, Jan. 1986.

COOPESS, Leonard J. אדם ('dm). In: HARRIS, R. Laird; ARCHER Jr., Gleason L.; WALTKE, Bruce K. Dicionário Internacional de teologia do Antigo Testamento. São Paulo: Vida Nova, 1998. p. 13-15.

DE VAUX, Roland. Instituições de Israel no Antigo Testamento. São Paulo: Vida Nova, 2008.

FÄRBER, Sonia Sirtoli. Considerações sobre a morte no Antigo Testamento: aproximações entre teologia e tanatologia. Anais do Congresso Internacional da Faculdades EST, São Leopoldo, v. 1, 2012. p. 1053-1065.

FOHRER, Georg. História da Religião de Israel. Santo André: Academia Cristã; São Paulo: Paulus, 2012.

FRERICHS, Wendell W. Death and Resurrection in the Old Testament. Word $\mathcal{E}$ World, v. 11, n. 1, p. 14-22, 1991.

JOHN, E. C. The Old Testament Understanding of Death. Indian Journal of Theology, v. 23, p. 123-128, 1974.

JOHNSTON, Philip S. Shades of Sheol: Death and Afterlife in the Old Testament. Leicester: Apollos; Downers Grove: InterVarsity Press, 2002.

MARCHADOUR, Alain. Morte e vida na Bíblia. São Paulo: Paulinas, 1985.

MARTIN-ACHARD, Robert. Da morte à ressurreição: segundo o Antigo Testamento. Santo André: Academia Cristã, 2015.

MAZZINI, Giovanni. On the meaning of SALMAWET, a discussed word in the Old Testament. Studi Epigrafici e Linguistici sul Vicino Oriente Antico, n. 16, p. 79-83, 1999.

MICHEL, Walter L. SLMWT, "Deep darkness" or "Shadow of Death"? Biblical Research, v. 29, p. 5-20, 1984.

MOWVLEY, H. Health and Salvation in the Old Testament. The Baptist Quarterly, v. 22, n. 3, p. 100-113, Jul. 1967.

89 Cf. MARCHADOUR, 1985, p. 8. 
ROWLEY, H. H. A fé em Israel: aspectos do pensamento do Antigo Testamento. São Paulo: Teológica, 2003.

SHEMESH, Yael. Suicide in the Bible. Jewish Bible Quarterly, v. 37, n. 3, p. 157-168, 2009.

SMICK, Elmer B. מוּת (mût). In: HARRIS, R. Laird; ARCHER Jr., Gleason L.; WALTKE, Bruce K. Dicionário Internacional de teologia do Antigo Testamento. São Paulo: Vida Nova, 1998. p. 820-822.

SMITH, Ralph L. Teologia do Antigo Testamento: história, método e mensagem. São Paulo: Vida Nova, 2002.

SMITH, Mark S. O memorial de Deus: história, memória e a experiência do divino no Antigo Israel. São Paulo: Paulus, 2006.

SOARES, Elizangela. Antigas variações sobre a vida após a morte. Revista Oracula, São Bernardo do Campo, v. 2, n. 4, p. 1-29, 2006.

SPRONK, Klaas. Good death and bad death in ancient Israel according to biblical lore. Social Science \& Medicine, v. 58, p. 987-995, 2004.

STONE, Anthony P. Does "Shadow of Death" mean "Deep darkness"? Journal of The Chicago Society of Biblical Research, v. LI, p. 53-57, 2006.

THOMAS, D. W. צלמות in the Old Testament. Journal of Semitic Studies, v. 7, p. 191-200, 1962.

VON SINNER, Rudolf. Quem decide sobre o fim da vida? Estudos Teológicos, São Leopoldo, v. 53, n. 2, p. 282-296, jul./dez. 2013.

WOLFF, Hans Walter. Antropologia do Antigo Testamento. São Paulo: Hagnos, 2008. 